\title{
Growing Plants on Atoll Soils
}

\author{
Earl L. Stone \\ Leo Migvar \\ William L. Robison
}

\section{February 2000}

U.S. Department of Energy

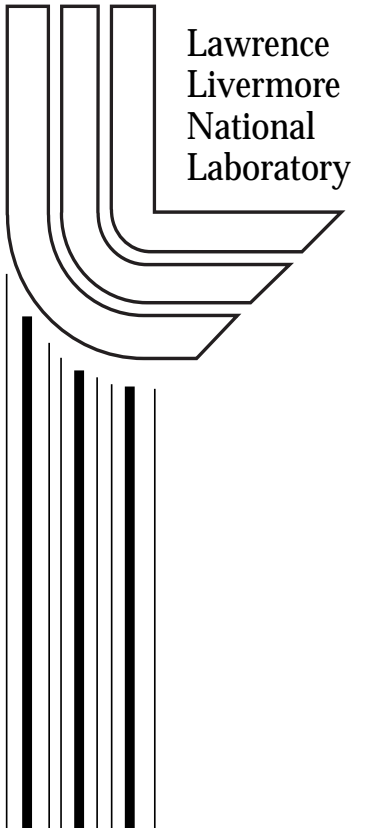




\section{DISCLAIMER}

This document was prepared as an account of work sponsored by an agency of the United States Government. Neither the United States Government nor the University of California nor any of their employees, makes any warranty, express or implied, or assumes any legal liability or responsibility for the accuracy, completeness, or usefulness of any information, apparatus, product, or process disclosed, or represents that its use would not infringe privately owned rights. Reference herein to any specific commercial product, process, or service by trade name, trademark, manufacturer, or otherwise, does not necessarily constitute or imply its endorsement, recommendation, or favoring by the United States Government or the University of California. The views and opinions of authors expressed herein do not necessarily state or reflect those of the United States Government or the University of California, and shall not be used for advertising or product endorsement purposes.

Work performed under the auspices of the U. S. Department of Energy by the University of California Lawrence Livermore National Laboratory under Contract W-7405-Eng-48.

This report has been reproduced directly from the best available copy.

Available to DOE and DOE contractors from the

Office of Scientific and Technical Information

P.O. Box 62, Oak Ridge, TN 37831

Prices available from (423) 576-8401

http://apollo.osti.gov/bridge/

Available to the public from the National Technical Information Service

U.S. Department of Commerce 5285 Port Royal Rd., Springfield, VA 22161 http://www.ntis.gov/

OR

Lawrence Livermore National Laboratory Technical Information Department's Digital Library http://www.llnl.gov/tid/Library.html 


\title{
G rowing Plants on A toll Soils
}

\author{
Earl L. Stone $\dagger$ \\ Leo M igvar* \\ William L. Robison \\ $†$ Adjunct Professor \\ University of Florida \\ Gainesville, FL \\ *Retired Agriculturist \\ Honolulu, Hawaii
}

M anuscript D ate: February 2000

\section{Law rence Livermore $\mathrm{N}$ ational Laboratory \\ U niversity of California • Livermore, CA • 94551}





\section{Contents}

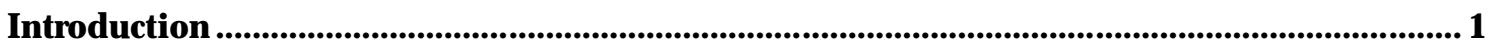

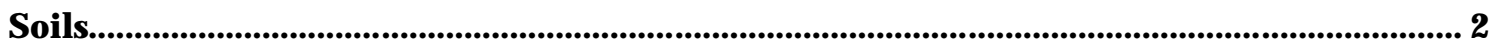

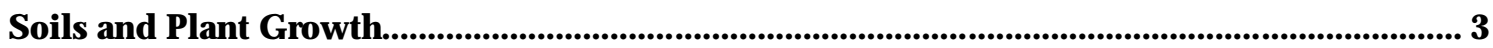

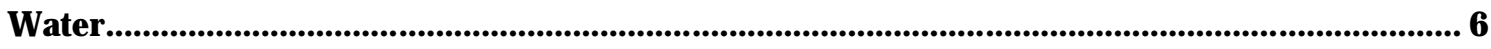

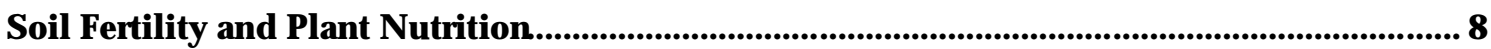

N itrogen (N)

Phosphorus (P)

Potassium (K)

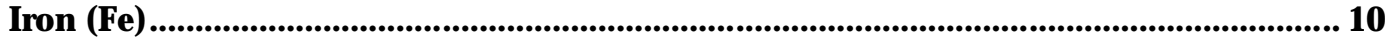

Zinc (Zn)

M anganese (M n)

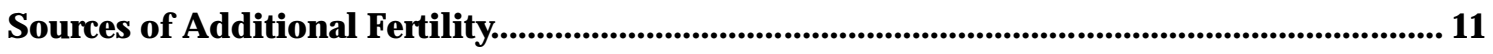

Selected Highlights of Environmental Factors Affecting Plant G rowth................................. 14

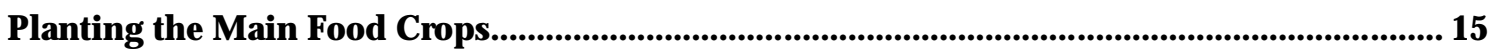

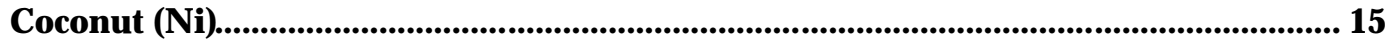

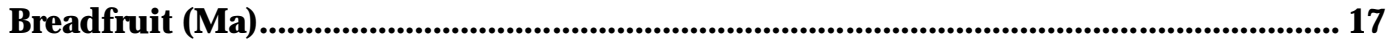

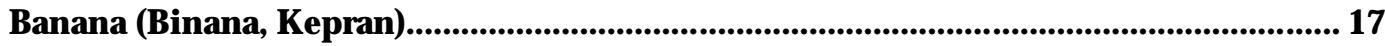

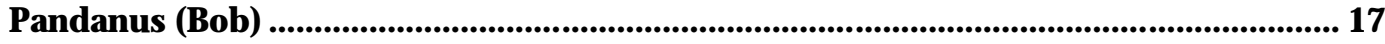

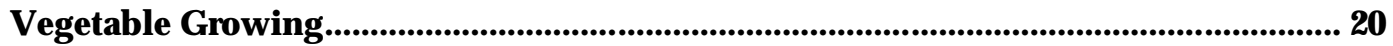




\section{List of Tables}

Table 1. Plant nutrients of concern in atoll soils........................................................... 9

Table 2. Commercial fertilizers for use on atoll soils......................................................... 12

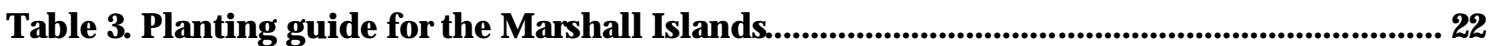

\section{List of Figures}

Figure 1. With time, the surface layer over white beach sand becomes darker and deeper as organic matter accumulates......................................................................................... 4

Figure 2. Soil preparation increases stem growth of 17-month old papaya (keinabu) on exposed, naturally compacted subsoil. All plants received equal fertilization and irrigation. . 5

Figure 3. M easurements on Bikini A toll illustrate how average monthly rainfall (thick bars) varies throughout the year on a "moderately dry" atoll........................................................... 7

Figure 4. Selection of coconut (ni) seedlings................................................................ 16

Figure 5. A useful method for hole preparation and planting of coconut (ni) seedlings........ 16

Figure 6. Three types of banana (binana, kepran) planting material ..................................... 18

Figure 7. The correct method of planting a banana (binana, kepran) sucker.......................... 19

Figure 8. How to place compost or other plant material in (a) a trench below a row of

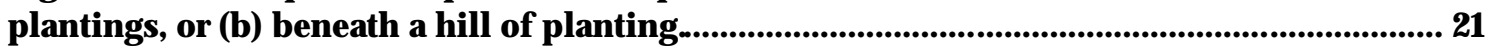




\section{Introduction}

Many years ago people living on atolls depended entirely on foods gathered from the sea and reefs and grown on land. Only a few plants, such as coconut (ni), Pandanus (bob), and arrowroot (mok-mok), could be grown on the lower rainfall atolls, although adequate ground water conditions also allowed taro (iaraj, kotak, wot) to be cultivated. On higher rainfall atolls, breadfruit (ma) was a major food source, and banana (binana, kepran), lime (laim), and taros (iaraj, kotak, wot) could be grown.

The early atoll populations were experts in growing plants that were vital to sustaining their nutrition requirements and to providing materials for thatch, basketry, cordage, canoe construction, flowers, and medicine.

They knew which varieties of food plants grew well or poorly on their atolls, how to propagate them, and where on their atoll they grew best. They knew the uses of most native plants and what the various woods were well suited for. Many varieties of $P$ andanus (bob) and breadfruit ( $\mathrm{ma}$ ) grew well with high rainfall, but only a few produced well on drier atolls. Such information had been passed down through the generations although some of it has been lost in the last century.

Today there are new plants and new varieties of existing plants that can be grown on atolls. There are also new materials and information on how to grow both the old and new plants more effectively. However, there are also introduced weeds and pests to control. Today, there is also an acute need to grow more of the useful plants adapted to atolls. Increasing numbers of people living on an atoll without an equal increase in income or food production stretches the available food supplies.

Much has been written about the poor conditions for plant growth on atolls. As compared with many places in the world where crops are grown, however, atolls can provide some highly favorable conditions. For instance, the driving force for plant growth is sunlight, and on atolls light is abundant throughout the year. Except on the driest of atolls, air temperature and humidity range only within limits set by the surrounding sea. There are no cold seasons, no frosts, no cold soils, no dry winds, and no periodic plagues of insects or diseases moving from miles away. Problems of soil drainage or salinity are few and easily recognized. Nor are there problems with acid soils, soil crusting, or erosion that challenge cultivators in many other areas. On the contrary, some of the black soils at the center of wide islands rank with the best soils of Russia and the American Midwest, except for their shortage of potassium and the uncertainties of rainfall. Some of these atoll soils contain more total nitrogen than many of the world's most productive agricultural soils and, in some, the total phosphorus content is so high as to be almost unbelievable-two to five tons of the element per acre.

Certainly, problems exist in growing plants on atolls. There are also some special concerns not encountered in other environments, such as the wind and salt spray near shore. The two major physical limitations, however, are inadequate rainfall in some years and in many places, and soil fertility limitations. The alkaline or "limy" make-up of atoll soils means that a few plant nutrients, especially iron, limit growth of many introduced plants, and this is difficult to correct. As elsewhere in the world, many-but not all- atoll soils lack enough nitrogen and/ or phosphorus for high yield, and all lack sufficient potassium.

There is no practical way of overcoming drought except by use of tolerant plants such as coconut (ni) and Pandanus (bob), plus collection and careful use of whatever water is available. There are opportunities to overcome nutritional limitations mentioned above, first, by intensive use of all organic debris and household wastes in small gardens and, second, by use of commercial fertilizers. Imported fertilizers are expensive, certainly, but much less so on a family basis than the equivalent costs of imported food. 
We have written this publication to help atoll residents grow plants adapted to atolls. It is only a beginning. All growers will still have to acquire experience with the rainfall and soils of their own holdings, as well as the plants and varieties suitable for the locality.

Most of our experience and examples were drawn from the Marshall Islands, but will apply to other deep ocean atolls with similar rainfall. The soils of coral islands close to continents or high islands may differ somewhat from those described here.

Since this publication will be distributed most widely in the Marshall Islands, we have added $M$ arshallese names for most of the plants mentioned.

\section{Soils}

A toll soils differ in several ways from almost all other soils that have been written about or discussed in agricultural literature. As a result, much information about growing plants on continents or high islands is either inappropriate or meaningless for atolls. For example, publications for gardeners and orchardists often give much attention to soil acidity, the problems that acid soils cause, and how to correct acidity by applying lime. But atoll soils are made up almost entirely of such lime - that is, calcium carbonate, with small amounts of magnesium carbonate. Such publications may also discuss silt and clay, the finest soil particles, which are indeed important in many continental soils. But soils of deep ocean atolls have no clay (except in microscopic amounts), and the silt-size particles (less than 0.02 inches in diameter) that occur in the oldest soils, consist of calcium carbonate, and are generally inconsequential for plant nutrition.

How are atoll soils formed? A nyone who has walked atoll beaches has seen most of the materials on which soils develop. There are sands, sometimes coarse (grains about four to eight, one-hundredths of an inch), sometimes fine, but often mixed in size. Many sands contain gravel-size fragments, and often there are beds of fine or coarse gravel as well as sands over gravel beds, and sands over cemented beach rock. Exposed coasts close to a reef edge often have beach ridges of rough cobbles or boulders thrown up by storms.

There are many combinations of sands, gravel, and rock. Over the centuries, storm waves have tossed sand and sometimes rocks on land surfaces above high tide level. Less commonly, great waves or storms have flooded parts of islands, depositing sand or rocks, or, occasionally, cutting away beaches and even long-established land.

Strong winds blowing over dry beaches carry medium-size sand grains into the vegetation behind the beaches. The deposits that accumulate over many years often are only a few to several inches thick, but occasionally sand dunes up to ten feet or more thick are formed. The grains in such deposits are quite uniform in size because wind cannot move large particles far, and because it carries the finest away as dust.

Soils begin to develop when plants first begin to grow in them. Fresh beach materials contain fragments of once-living materials-coral organisms, algae, shells, crabs, fish, etc. The decay of these materials provides a small amount of all nutrients that plants require, and gives rise to the hardy grasses, vines, and shrub, which spread over new land soon after rains wash out the excess salt.

Plant roots, leaves, and stems decay at differing rates, eventually forming a black residue or "humus," which slowly accumulates. Such residues and plant materials in various stages of decay before humus is created modify the soil and make it more favorable for plant growth. As the organic matter content of the upper soil layer increases from 1 or $2 \%$ in young sands to as much as 10 to $15 \%$ in the black soil of wide islands, this layer becomes more easily 
penetrated by roots, holds more water after rains, and provides a much greater store of plant nutrients. Such a large increase in organic matter requires a long timeprobably centuries-to develop. A soil high in organic matter is a valuable resource.

\section{Soils and Plant G rowth}

The following four soil features should be considered when growing plants.

The first feature is rockiness or stoniness that would interfere with the establishment of young plants and their cultivation. Coral rocks are somewhat porous, especially as they age; however, areas of loose rock can sometimes be planted with strong-rooted trees, such as coconut (ni) and some shade trees. In other places, cemented sand or thick layers of gravel lie just beneath a sandy surface and restrict deep root development. This possibility is easily examined by digging a test pit.

The second feature is organic matter content. As might be expected, organic matter is higher as the soil becomes darker, but only to a certain point. The change in soil color from white to light brown, to medium gray or brownish gray, to dark gray, and then to black (when moist), covers the range in organic matter from $1 \%$ or less to about 5 or $6 \%$. Although the soil cannot become any blacker than black, the organic matter content of black soils can still increase up to $10 \%$ or more, and become deeper. Figure 1 illustrates this range in colors and depth

In general, increases in organic matter mean greater water storage, easier root development, and much higher fertility. All of these factors favor rapid growth of new small seedlings. They also favor rapid growth of weeds, which calls for early weed control.

When first cultivated, the black soils may supply enough available nitrogen for good growth of most short-season crops. This amount decreases the longer the soils are cropped, however, so that added nutrients are soon needed. Lighter colored soils, with less than 5 or $6 \%$ organic matter, can be productive for cultivated crops of any kind, but from the beginning require additions of organic materials or commercial fertilizers, plus closer attention to adequate water supply.

The third feature is the friability or "Iooseness" of soil. This affects how rapidly and thoroughly plant roots spread sideward through the surface soil, and how well they penetrate downward to use stored soil water during dry periods. For example, in some soils coconut (ni) roots grow downward six feet or more. During dry seasons, they extract almost all plantavailable water within rooting depth and so maintain some degree of active growth. In contrast, cemented sands or other restrictive growth layers located within a few feet of the surface prevent deep root development, and reduce nut size and numbers when rainfall is low. Some long-season fruit and vegetable crops like pumpkin (banke), tomato, and papaya (keinabu) also root deeply when soils are easily penetrated.

In soils that seem otherwise suitable, two conditions may limit root penetration. These are, (a) the natural packing of many water-deposited sands below a depth of two feet, and (b) artificial compaction of the surface and near-surface layers, usually by vehicle traffic.

The naturally packed subsoils are not dense, but the particles are rough-surfaced and so arranged that they resist displacement. It is almost impossible to drive a large wooden stake into such layers, and penetration by roots is limited. The strong roots of coconut (ni) and trees such as cordia (kona) cannot grow freely, but follow soft spots and channels of previous roots. Roots of papaya (keinabu) do not penetrate such layers well and so remain in the upper soil.

Artificially compacted surface and nearsurface soils cause serious and long-lasting problems whenever cars, trucks or bulldozers run over soil repeatedly, especially when the soil is wet. Black surface soils that would normally weigh 60 to 70 


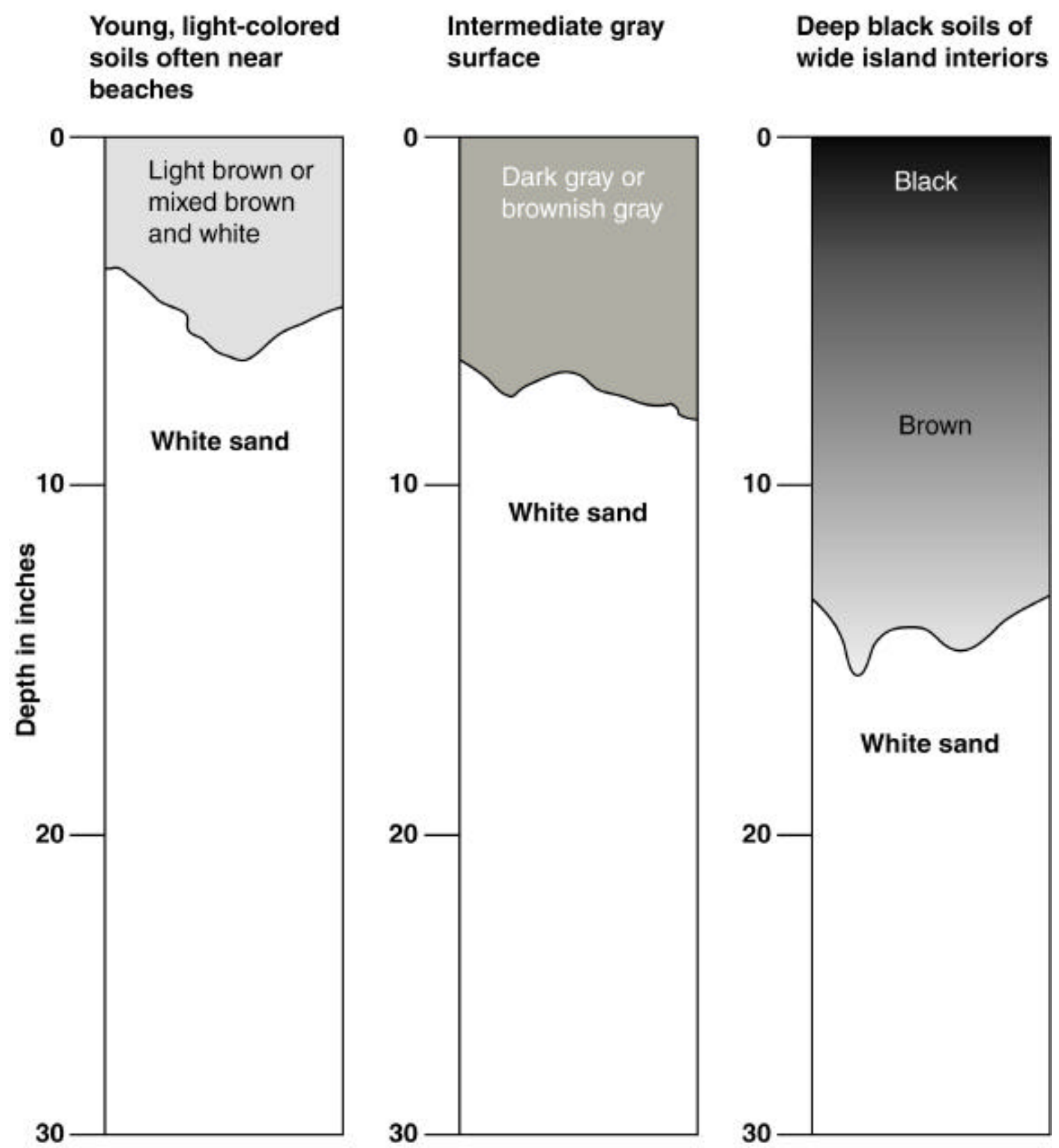

Figure 1. With time, the surface layer over white beach sand becomes darker and deeper as organic matter accumulates. 
pounds per cubic foot are squeezed into hard blocks weighing up to 110 pounds per cubic foot, and these may remain solid for at least 30 years. They have no pores or channels large enough for roots to grow in. Even when the surface has been loosened, the layers just below are sometimes packed so firmly that they resist penetration even by coconut (ni) roots.

Figure 2 shows how loosening the naturally packed subsoil improved the growth and fruiting of papaya (keinabu). In this case, the upper 16 inches of surface soil had been scraped off, leaving a white sand subsoil as the planting site. Some papaya (keinabu) were planted directly in this firm sand. For the others, large pits were dug and refilled, breaking up the natural soil packing. Some pits were simply refilled without any addition; others had a bushel or two of old coconuts (ni) and husks added as the pit was refilled. This addition increased growth still more, because the material decayed and further increased the looseness and soil pore space, which aided root growth. All three treatments received the same amount of irrigation when young, the same amount of fertilizer, and the same weeding and care. Papaya (keinabu) stem growth in soils that were only loosened, without organic addition, was about 4.5 times greater than the stem volume of the untreated trees (planted in the firm sand). Addition of coconut (ni) husks and old nuts raised stem volume to more than 7 times greater than the untreated. Fruit production of the treated trees was earlier and much greater.

The fourth feature is the depth to a water table, and the saltiness or freshness of that water. Most habitable islands are probably eight to twelve feet above the underlying groundwater level, although sand dune surfaces may be still higher. Wide islands sometime include low-lying areas where fresh or salty water is much closer. Other land areas are close enough to fresh water that people long ago excavated large trenches or basins in which to grow taro (iaraj). Today, lime (laim) and bananas (binana, kepran) are sometimes grown in the sides of such pits.

Attention to the preceding four soil features-stoniness, organic matter, friability, and rooting depth-and to the groundwater together with the expected seasonal rainfall provide bases for determining how to grow plants on a particular area.

\section{Water}

All plants require water for growth and production. During severe droughts some plants wilt and die, whereas others remain alive but produce poorly or not at all. After the soil is rewetted, some kinds grow again and produce but others never grow well after droughting. Where the soil permits, deep-rooting plants may reach water stored in the subsoil.

Actively growing plants in full sun lose surprisingly large amounts of water from their leaves. Water loss from a continuous leaf cover-as from well-grown pumpkin (banke) or sweet potato (biteto tonal)-will amount to one-tenth to two-tenths of an inch per day when soil moisture is adequate. [Water loss from soil or leaves can be expressed in the same way as rainfall, that is, as inches per day or per month, and so on.]
A loss rate of only one-tenth of an inch per day from $66 \times 66$ foot garden (one tenth of an acre) amounts to 270 gallons of water per day. Young plants use less water than this before their leaves cover the ground. They also use less water if a dry soil does not supply that amount, but in this case they also grow less. Therefore, even a shortseason crop consumes a large amount of water. Supplying all of this water by irrigation is rarely feasible on atolls except for very small areas. Most field grown crops must depend on water supplied by natural rainfall.

A verage yearly rainfall varies greatly among the many atolls of the Pacific region. Even within a single island group like the $M$ arshall Islands, the range is very large (Figure 3). This means that the varieties of plants and treatments suitable for one atoll 


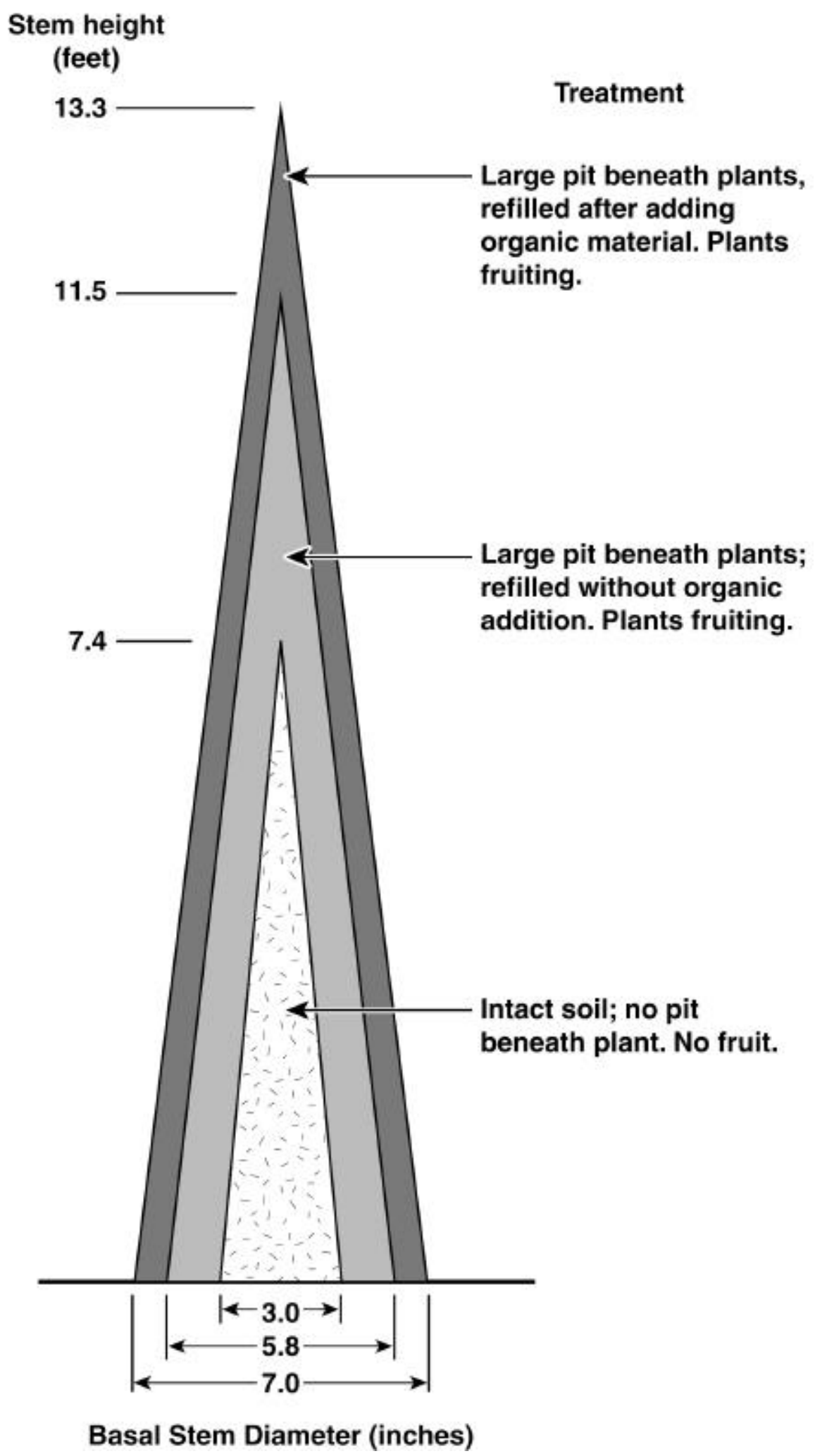

Figure 2. Soil preparation increases stem growth of 17-month old papaya (keinabu) on exposed, naturally compacted subsoil. All plants received equal fertilization and irrigation. 


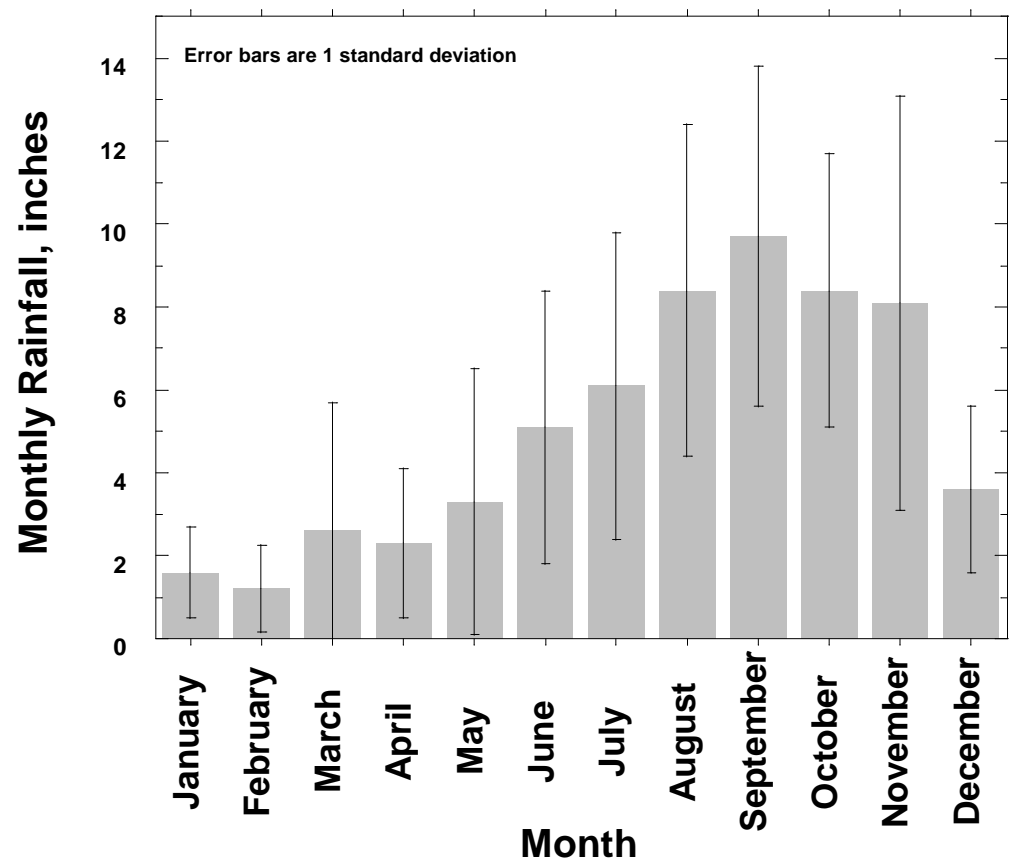

Figure 3. Measurements on Bikini Atoll illustrate how average monthly rainfall (thick bars) varies throughout the year on a "moderately dry" atoll. The thin lines in and above each bar show the range of about two-thirds of the individual values. The average yearly rainfall is 60 inches, but it has ranged from 32 to 95 inches over the 15 years of record.

may not be appropriate for another with much higher or lower rainfall. Furthermore, droughts occur at least occasionally on most atolls, even in months that usually have adequate rainfall. Accordingly, growers on most atolls need to be aware of how to collect, save, and use wisely all of the water available to them. For example, some or all rain runoff from roofs is often lost for lack of adequate gutters and storage tanks. On some atolls, the water used for showers, washing, and food preparation-sometimes called "gray water" - is too valuable to waste because it can be diverted to plants during dry periods.

Storage in the soil is by far the greatest source of water for plants between rains. Although a grower cannot control the amount of rain that falls on his land, he does have some influence on effective use of that water. For example, the weeds in a poorly tended garden can consume as much or more of the stored soil water than the crop plants. On the other hand, mulches along plant rows shade the soil surface and reduce evaporation of water for some days after rain.

Both water storage in soil, and its use, can be expressed as inches of plant-available water per foot of soil depth, to whatever depth plant roots extend. In general, after heavy rains, white, light brown, or light gray sands will retain 1 to 1.5 inches of water per foot of depth without much difference between the surface and subsoil. So a coconut (ni) grove rooting to a depth of 6 feet can obtain as much as 6 to 9 inches of water from a fully wetted soil. Gray to dark gray soils hold 1.5 to 2.0 inches of water per foot in the dark colored layer (which may be may not be appropriate for another with much less than a foot thick), and 1 to 1.5 inches per foot below this. Dark black surface soils can retain 2.0 to 2.5 inches per foot. Such surfaces might be as much as a foot thick, usually with gray-brown soil 
beneath, and white sand below that. Very gravelly or rocky soils hold less water than the values given. After stored water is extracted by roots, the soil remains dry until it is again recharged by heavy rains. When droughts are prolonged, subsoils can remain dry for a year or more.

\section{Soil Fertility and Plant Nutrition}

Green plants require several "nutrients" or chemical elements for growth and fruiting. These are normally obtained by roots from the soil. (A few plants and microorganisms, however, can take nitrogen from the air, as noted below). When the amount of any nutrient absorbed by a plant is small in terms of its needs, growth is slow, leaves may discolor or die, and roots fail to extend as they should.

Table 1 lists the nutrients of chief interest to atoll growers. Some essential nutrients of great concern in other parts of the world, such as magnesium, molybdenum, and boron, are omitted because they are abundant in atoll environments. Therefore, this section contains a discussion of only the six plant nutrients most likely to be in short supply on atolls.

\section{Nitrogen (N)}

Of these six nutrients, nitrogen is the one that plants require in the greatest amount. Nitrogen makes up about 3 to $5 \%$ of the soil's organic matter. It is released slowly from this organic matter, and from the decay of any composts, manures, or fresh green plant material. Generally, the higher the organic matter content of soil the more nitrogen plants can obtain.

One large group of plants, the legumes, is exceptional in having bacterial nodules on their roots that can convert nitrogen gas in air to "fixed" forms that are usable by the plant. This group includes beach pea or Vigna (marckinjojo), Canavalia (kana), garden beans (piin), and the introduced tree, Leucaena. A nother introduced tree, Australian pine (Casuarina) (mojnoki, blue kam), is not a legume but also fixes nitrogen.

\section{Phosphorus (P)}

The availability of phosphorus is of equal importance to nitrogen in plant growth, although the amount in leaves is only about one-tenth the weight of nitrogen. One of the remarkable features of atolls is the extremely high content of phosphorus in many older and some new soils. This phosphorus is deposited by nesting seabirds that feed on fish often many miles from land. Unlike potassium, phosphorus is retained in the soil. The current amounts represent accumulations over hundreds, or perhaps thousands, of years of bird nesting. A few islands actually have thin layers of brown calcium phosphate sand and cemented rock. Many island interiors, however, are also relatively rich in phosphorus, often containing 0.5 to $1.5 \%$ or more in the surface soil ( 6 to 8 inches depth). To purchase and add such amounts would cost thousands of dollars per acre.

Certain birds, such as the crested tern and sooty tern, nest on the ground in grassy or sparsely vegetated areas near the coast, so some young soils also have accumulated phosphorus. Probably only a small fraction of all young soils on an atoll have been so affected.

\section{Potassium (K)}

Potassium is needed by plants in fairly large amounts, from about half as much as nitrogen to nearly as much. Yet the supply of potassium in atoll soils is very small. The amount that can be held there depends on the organic matter content, and any excess above this amount is soon washed out of the soil by heavy rains. 
Table 1. Plant nutrients of concern in atoll soils.

\begin{tabular}{|c|c|c|}
\hline N utrient & $\begin{array}{l}\text { A pproximate } \\
\text { leaf concentration } \\
\text { percent (or p.p.m.) } \\
\text { of dry weight }\end{array}$ & $\begin{array}{l}\text { Natural occurrence in soil, and } \\
\text { sources for plants in atoll soils }\end{array}$ \\
\hline \multicolumn{3}{|c|}{ The big three major nutrients: } \\
\hline Nitrogen $(\mathrm{N})$ & 1.5 to $4 \%$ & $\begin{array}{l}\text { Soil organic matter. All green organic materials, } \\
\text { composts, manures, and fish wastes. Nitrogen- } \\
\text { fixing plants. }\end{array}$ \\
\hline Phosphorus (P) & 0.1 to $4 \%$ & $\begin{array}{l}\text { Soil organic matter, (especially black soils } \\
\text { enriched by bird guano long ago). Green organic } \\
\text { materials, bones, wood ash, and fish waste. } \\
\text { "Island phosphate"-brown sand and rock on } \\
\text { some bird islands. }\end{array}$ \\
\hline Potassium (K) & 0.5 to $3.0 \%$ & $\begin{array}{l}\text { Small amounts held by soil organic matter. } \\
\text { Green organic materials, coconut (ni) husk, } \\
\text { wood and husk ash. Continuous small addition } \\
\text { by sea spray. }\end{array}$ \\
\hline \multicolumn{3}{|c|}{ Three micronutrients frequently deficient in plants: } \\
\hline Iron (Fe) & $\begin{array}{l}20 \text { to } 100 \text { parts } \\
\text { per million }\end{array}$ & $\begin{array}{l}\text { Mostly in soil organic matter. All green } \\
\text { organic materials, compost, manures, etc. Iron } \\
\text { chelate as soil amendment. Iron sulfate as leaf } \\
\text { spray. }\end{array}$ \\
\hline Manganese (Mn) & $\begin{array}{l}20 \text { to } 100 \text { parts } \\
\text { per million }\end{array}$ & $\begin{array}{l}\text { Organic matter and materials as above } \\
\text { Manganese sulfate and chelates as soil addition } \\
\text { or leaf spray. }\end{array}$ \\
\hline Zinc (Zn) & $\begin{array}{l}20 \text { to } 200 \text { parts } \\
\text { per million }\end{array}$ & $\begin{array}{l}\text { Organic matter and materials as above } \\
\text { Fish waste and bird guanos. Zinc sulfate as soil } \\
\text { addition or spray. }\end{array}$ \\
\hline
\end{tabular}


Seawater contains a small amount of potassium (about 380 parts per million), and salt spray blown inland is the major source of added potassium. This is true in the long run, but the amount added in one year is too small to meet the needs of short-season plants. After a few crops, often only two or three, the potassium supply is reduced to such a low level that plants no longer grow well without some addition of potassium.

Although no nutrient can replace a plant's need for water, sufficient amounts of potassium increase the ability of some plants to withstand drought.

\section{Iron (Fe)}

Plants require very small amounts of iron, usually only 20 to 100 parts per million. Because of this, and the fact that soils over much of the world have adequate supplies for plants, iron is usually grouped as one of the "micro-nutrients," "minor elements," or "trace minerals." Without enough iron, however, plant leaves become pale green, yellow, or even white; root development is slow; and the plants fail or are stunted. N ative atoll plants have adjusted to the limited supply. Even so, the leaves of beach pea (morckinjojo), Canavalia (kana), and Triumfetta (atat) on new vines running out over fresh sand are often yellow because these vines absorb little or no iron from sand without organic matter. Native plants growing in soils with a higher organic content usually can absorb enough iron to remain green. Lime (laim), banana (binana, kepran), and papaya (keinabu), however, as well as a great number of introduced crop plants and ornamentals, do not absorb iron well from the limy atoll soils.

How can such plants be treated? Adding iron metal, iron rust, or most iron compounds is useless because roots in atoll soils cannot absorb such iron. At present, there are three ways of supplying iron to plants that cannot get enough from untreated soil, plus a fourth method that has been little tested.

1. An abundance of composts, manures, or organic materials of any sort can be used to add iron to soil. These materials should be placed in furrows close to the rows or in small pits for individual plants. The materials should be in small chunks or masses ( 0.5 to 2 cupfuls in size), rather than being finely divided and spread through the soil. Well-packed and thick mulches of almost any kind of organic wastes, grasses, vines, etc., piled around a plant are likely to be effective during rainy seasons when the mulch is moist most of the time.

2. A commercial product, Sequestrene 138-Fe, sometimes called "red iron," is very effective on atoll soils. Its cost and difficulty in obtaining it in the islands may limit its use to only large-scale growers. (There are several other commercial products, but this is the only one effective on atoll soils.)

3. Plants can absorb iron from dilute solutions of iron salts or chelate sprayed on the leaves. As mentioned later, such treatments may be suitable only for small or valuable plants.

4. Strips of green coconut (ni) husk (as from drinking nuts), soaked overnight in a dilute solution of iron sulfate (ferrous iron, not ferric), turn deep purple or black as they react with iron. In preliminary studies, such treated husk, buried very close to germinating seedlings, supplied the iron needed for growth over several months.

\section{Zinc (Zn)}

Like iron, zinc is a micronutrient that plants need in only small amounts. Green leaves of various plant contain only 25-100 parts per million.

A toll soils have a low zinc content, but this seems to meet the needs of native plants. Some introduced vegetables and ornamental plants, however, are much more sensitive to low zinc in the soil, especially when commercial fertilizers, such as phosphorus, are applied. In experiments on Bikini A toll, small applications of zinc sulfate to soil prevented zinc deficiency in several fertilized crops. 


\section{M anganese(M $\mathrm{n})$ [N ot to be confused with magnesium (M g)]}

The third micronutrient of concern in atoll soils is manganese. Insufficient manganese causes brown spotting or yellow-green mottling of leaves on some kinds of plants, and yellowing between the veins on others. This latter may resemble signs of iron deficiency. Manganese deficiency is much less common than iron deficiency on atoll soils, but can be expected to occur on some crops when commercial fertilizers are used without organic additions.
Coconuts (ni) or seedlings ready to be planted can be treated with iron, zinc, and manganese by a simple procedure: a hole is cut or drilled in the husk (not into the nut). One-half ounce each of iron sulfate and manganese sulfate plus one-quarter ounce zinc sulfate are added, and the hole is plugged or loosely sealed. These materials diffuse in the husk and are eventually absorbed by roots of the developing seedling. This treatment may not be needed on the best soils, but elsewhere it prevents yellowing and increases growth over the first two to three years.

\section{Sources of Additional Fertility}

As discussed previously, soils with black, highly organic surfaces are more fertile than the white, brownish, or gray soils on the same island. Repeated cultivation and removal of crops from any soil takes away some of the nutrient elements, and sooner or later reduces productivity unless these nutrients are replaced. Thus, a grower must consider how to maintain or even increase fertility of gardens or intensively cropped areas.

Essentially, there are only two ways to do this on atolls: First, add all organic materials, manures, and so on that can be obtained. Such materials contain some amount of the nutrients needed for plant growth and will release these as they decay. The organic substance itself has additional benefits as mentioned earlier. Second, use commercial fertilizers to supply the additional nutrients needed for vigorous growth and high productivity. At the same time, conserve soil organic matter by reducing exposure to full sun, and apply whatever organic materials are available.

Every household produces food preparation wastes and garbage. Some of this may be fed to pigs or chickens, but the remainder, together with wood ashes, yard wastes such as leaves, and coconut (ni) husks can be used to increase soil productivity. One way, al ready in widespread use, is to dump such materials in pits dug at places where one intends to plant banana (binana, kepran), breadfruit (ma), papaya (keinabu), or other large plants. A nother is to bury them in shallow trenches in garden areas. Still another is composting all such materials in covered pits or large containers, which allows partial decay before application to soil. Composting is uncommon or non existent on most atolls, but is widely used in many other Pacific areas where cultivation is intensive.

Other sources of organic material are vines, grass, and leaves gathered from uncultivated areas. Such materials can be used as surface mulches in small areas, or composted, or buried in pits. Many tons are required to supply enough nutrients for large plots, and so such gathering is useful mainly for small garden plots.

Commercial fertilizers have been used for several years to grow many kinds of plants on Enewetak, Bikini, and Majuro Atolls in the Marshall Islands, and probably elsewhere. At present, however, commercial fertilizers are almost unavailable to most growers in the Marshall Islands and many other atolls. Accordingly, this section contains only a simple introduction to their use. Nevertheless, any large increase in food production on atolls with suitable rainfall will require both widespread availability of these fertilizers, and development of the skills to use them efficiently. Table 2 lists the common fertilizers useful on atoll soils.

There are also many other specialized formulations. One such is a pelletized, mixed fertilizer that releases nutrients 
Table 2. Commercial fertilizers for use on atoll soils.

\begin{tabular}{|c|c|c|}
\hline M aterial & \multicolumn{2}{|c|}{$\begin{array}{l}\text { Approximate } \\
\% \text { nutrient }\end{array}$} \\
\hline \multicolumn{3}{|c|}{$\begin{array}{l}\text { I Individual nutrients and nitrogen-phosphorus combinations. } \\
\qquad \mathbf{N} \text { itrogen-for mixing with soil or composts }\end{array}$} \\
\hline Urea & $46 \%$ & Nitrogen \\
\hline A mmonium nitrate & $34 \%$ & Nitrogen \\
\hline A mmonium phosphate-DAP & $\{18 \%$ & Nitrogen \\
\hline & $\{20 \%$ & Phosphorus \\
\hline A mmonium sulfate & $21 \%$ & Nitrogen \\
\hline \multicolumn{3}{|c|}{ Nitrogen-for surface application } \\
\hline Sodium nitrate & $16 \%$ & Nitrogen \\
\hline Ordinary superphosphate & $7-9 \%$ & $\begin{array}{l}\text { Phosphorus } \\
\left(=16-20 \% \mathrm{P}_{2} \mathrm{O}_{5}\right)\end{array}$ \\
\hline Triple superphosphate & $19-23 \%$ & $\begin{array}{l}\text { Phosphorus } \\
\left(=43-53 \% \mathrm{P}_{2} \mathrm{O}_{5}\right)\end{array}$ \\
\hline \multirow[t]{2}{*}{ A mmonium phosphate-DAP } & $\{18 \%$ & Nitrogen \\
\hline & $20 \%$ & $\begin{array}{l}\text { Phosphorus } \\
\left(=46 \% \mathrm{P}_{2} \mathrm{O}_{5}\right)\end{array}$ \\
\hline \multicolumn{3}{|l|}{ Potassium } \\
\hline Potassium chloride (also called muriate of potash) & $50 \%$ & $\begin{array}{l}\text { Potassium } \\
\left(=60 \% \mathrm{~K}_{2} \mathrm{O}\right)\end{array}$ \\
\hline \multicolumn{3}{|l|}{ Iron } \\
\hline Sequestrene 138Fe (red iron) & $6 \%$ & Iron \\
\hline Iron sulfate $\left(\mathrm{FeSO}_{4} \bullet \mathrm{H}_{2} \mathrm{O}\right)$ & $33 \%$ & Iron \\
\hline \multicolumn{3}{|l|}{ Zinc } \\
\hline Zinc sulfate $\left(\mathrm{Zn} \mathrm{SO}_{4}\right)$ & $40 \%$ & Zinc \\
\hline \multicolumn{3}{|l|}{ M anganese } \\
\hline Manganese sulfate $\left(\mathrm{Mn} \mathrm{SO}_{4} \bullet 4 \mathrm{H}_{2} \mathrm{O}\right)$ & $24 \%$ & Manganese \\
\hline \multicolumn{3}{|l|}{$\begin{array}{l}\text { II M ixed fertilizers- expressed as proportions } \\
\text { Examples: }\end{array}$} \\
\hline \multirow[t]{3}{*}{$10-10-1010 \%$} & $10 \%$ & Nitrogen \\
\hline & $4.4 \%$ & $\begin{array}{l}\text { Phosphorus } \\
\left(=10 \% \mathrm{P}_{2} \mathrm{O}_{5}\right)\end{array}$ \\
\hline & $8.3 \%$ & $\begin{array}{l}\text { Potassium } \\
\left(=10 \% \mathrm{~K}_{2} \mathrm{O}\right)\end{array}$ \\
\hline \multirow[t]{3}{*}{$15-15-1515 \%$} & $15 \%$ & Nitrogen \\
\hline & $6.6 \%$ & Phosphorus \\
\hline & $12.5 \%$ & $\left(=15 \% \mathrm{~K}_{2} \mathrm{O}\right)$ \\
\hline
\end{tabular}

Notes: (1) Commercial fertilizer labels list phosphorus as the oxide, $\mathrm{P}_{2} \mathrm{O}_{5}$, and potassium also as the oxide, $\mathrm{K}_{2} \mathrm{O}$. (2) Urea, ammonium fertilizers, and mixed fertilizers should never be applied on atoll soil surfaces.

slowly over a long period. This is desirable for many potted plants, and for somesmall

nurseries, but these types of fertilizers are generally more expensive. Most growers 
will be more concerned about the cost per unit of nutrients.

Many prospective garden sites and house yards are on soils that either were not high in nutrients originally, or have long grown only grass and shrubs. Plants grown in such soils are likely to require all major nutrients, as found in mixed fertilizers. A 15-15-15 material contains $1 \frac{1}{2}$ times the nutrients as an equal weight of 10-10-10; this needs to be taken into account when comparing costs of different fertilizers. Both individual nutrient carriers, and mixed fertilizers having nutrient ratios different from the 1:1:1 proportion illustrated in Table 2 (for example, 6-10-15), will eventually be used on atolls but are not discussed here.

The following list of do's and don'ts provides a few guides for growers who have never used fertilizers before:

1. Like table salt and seawater, most fertilizers will corrode metal. Do thoroughly wash any metal containers, tools, truck bodies, etc. that have been in contact with fertilizers.

2. Like table salt, fertilizers will become sticky or cake up when exposed to very moist air. A mmonium nitrate and fertilizers containing it can absorb so much moisture from the air they actually drip. Do store fertilizers in plastic bags or wrappings, and in a dry place.

3. Don't spread fertilizers containing urea or ammonium compounds on the surface of atoll soils. The ammonium will volatilize when in contact with limy soil, and the costly nitrogen it contains will be lost to the air without benefiting plants. All such materials either should be well mixed with soil, or placed in shallow furrows or holes and immediately covered with soil. Of the nitrogen fertilizers in Table 2, only sodium nitrate can be spread on the soil surface without major loss.

4. Don't use too much or too little fertilizer. A reasonable "target amount" for a first application to most garden crops is 500 pounds of $10-10-10$ per acre. This amounts to 1.1 pounds per 100 square feet of soil surface, or a little more than one-half of a coffee can (12 ounces). This amount would also treat 30 to 40 feet of row crops. The same amount of $15-15-15$ or $16-16-16$ would treat 150 square feet or 45 to 60 feet of row. For row crops, dig a furrow 3 to 4 inches deep and 6 to 8 inches away from the seed or seedling. Add the fertilizer and immediately cover with soil.

5. Don't place fertilizer too cl ose to seeds or seedlings. Doing so can "burn" leaves or prevent seeds from sprouting. Keep the fertilizer 6 to 10 inches away from plants unless the soil is frequently wet.

6. Do continue adding organic matter and using surface mulches as much as possible.

7. Don't think that mixed fertilizers can either cause or cure the leaf yellowing that is due to lack of iron uptake in susceptible plants. The only feasible treatments are digging organic materials into the soil before planting, or spreading a suitable iron chelate such as Sequestrene 138Fe on the soil next to the plant, or, sometimes, three sprays of iron compounds on the leaves.

8. Do recognize that nitrogen and potassium fertilizers are easily washed out of the soil by heavy rains-three inches or more per week on wet soil. Heavy fertilizer applications to small crops during rainy months are often wasted. Three approaches to keep plants supplied with nutrients during such periods are these:

a. Before planting garden crops, dig in manure, compost, and other highquality organic material as recommended.

b. Apply mixed fertilizers in small amounts and frequently-every week or two.

c. If fertilizers are al ready in a furrow as recommended, cover them with a narrow strip of plastic, 8 to 10 inches wide, holding it down with soil, rocks, or pins. Old boards or any such material can provide a "roof" to prevent rain from washing directly 
through the fertilizer below. If the soil in the furrow is moist at the beginning, it will stay moist enough

for root activity.

\section{Selected Highlights of Environmental Factors Affecting Plant G rowth}

\section{Environmental Factor}

Wind and salt spray

Soil

Water

Nutrients

\section{Response}

No coastal area is free from frequent or occasional damage; however, in part natural shoreline scrub protects plants being damaged. Where needed, establish scrub and windbreaks of $\mathrm{P}$ andanus (bob) or A ustralian pine (mojnoki, blue kam).

A ppraise both capacity for plant growth and limitations. Pandanus (bob) and coconut (ni) will grow on loose rock and rocky soils. Deep black soils are best for garden crops. M ost deep soils free of salt can be made productive with sufficient effort. Add organic material to increase nutrient supply and water retention. Promote root growth by deep digging.

Maximize benefit of natural rainfall by:

a. Choosing suitable kinds and varieties of plants. .

b. Increasing soil moisture storage and rooting depth. .

c. Eliminating weeds, and mulching heavily to reduce soil water loss. .

Store excess roof water and use household gray water to maintain plants in dry seasons

Supplement natural soil supplies by:

a. Adding organic materials of all kinds.

b. Using commercial fertilizers effectively.

Small "kitchen gardens" can be made productive by heavy additions of organic materials. Commercial fertilizers are not readily available on many islands but are needed for large increases in food production.

\section{Planting the Main Food Crops}

Coconut (ni), Pandanus (Bob), and breadfruit (ma) remain important in the diets of many atoll people. These plants are well known, adapted to atoll soils, longlived, and take relatively little care once well established. Accordingly, they deserve first attention whenever planting for food production is being considered.

The following brief descriptions assume that commercial fertilizers are not yet available to most growers except, perhaps, for some special purposes. This means that 
all nutrients needed for plant growth must come either from the soil itself or be added in organic materials as discussed earlier.

The black soils of island interiors often have sufficient available nutrients for several crops, with the exception of potassium. Although cooking-fire ash can supply small quantities of this nutrient, the amount of ash available can treat only a small area. Most light colored soils are so low in available nutrients that only coconut (ni) or Pandanus (Bob) will grow well there without treatment.

The quantities of "high quality" organic materials, such as manures, leaves, and vines of beach pea, are limited on most islands. Coarse materials, such as coconut (ni) leaves and unrotted husks, are lower in nutrients and difficult to handle as mulches. As a result, many growers will never have a sufficient amount of organic additions and mulches for more than a small garden plot.

\section{Coconut (Ni)}

Old age and lack of soil nutrients have reduced productivity of coconut (ni) groves in much of the Marshall Islands and probably elsewhere also. Therefore, most new plantings will be replacing old groves.

Four important steps to good coconut (ni) planting are:

1. Select good seed nuts from highyielding palms in an area with other high-yielding palms.

2. Select fast-growing healthy seedlings (Figure 4) after sprouting the nuts in a nursery, as described below.

3. Prepare the planting site to give seedlings good opportunities for growth. When planting white to gray soils, consider placing iron-zincmanganese sulfates in husk.

4. Remove brush from an 8-footdiameter circle around each seedling. Apply mulch around seedlings. Repeat four times a year.

When growing seedlings, place seed nuts in a nursery about December so they can be field planted at the beginning of the rainy season. Place nuts about one foot apart in a shaded area. After 3 to 4 months discard all nonsprouted and slow-sprouting nuts. Later, at the third-leaf stage, select for leaf number, leaf size, and collar diameter. Reject any with tall thin stems or an indication of disease or insects.

New plantings should be spaced about $25 \times 25$ feet. For best results, dig a hole about two feet square by two feet deep. In established groves this will cut roots that otherwise would compete with the new seedling. Fill the hole halfway with organic materials, such as coconut (ni) husks, and then put in good topsoil to within six inches of the soil surface. Place the seedling on this and fill with soil to near the top of the nut (Figure 5).

When replacing an existing grove, begin thinning in the second year, taking out about $50 \%$ of the old palms, including the least productive. Remove the rest of the old palms when the new ones first start producing. 


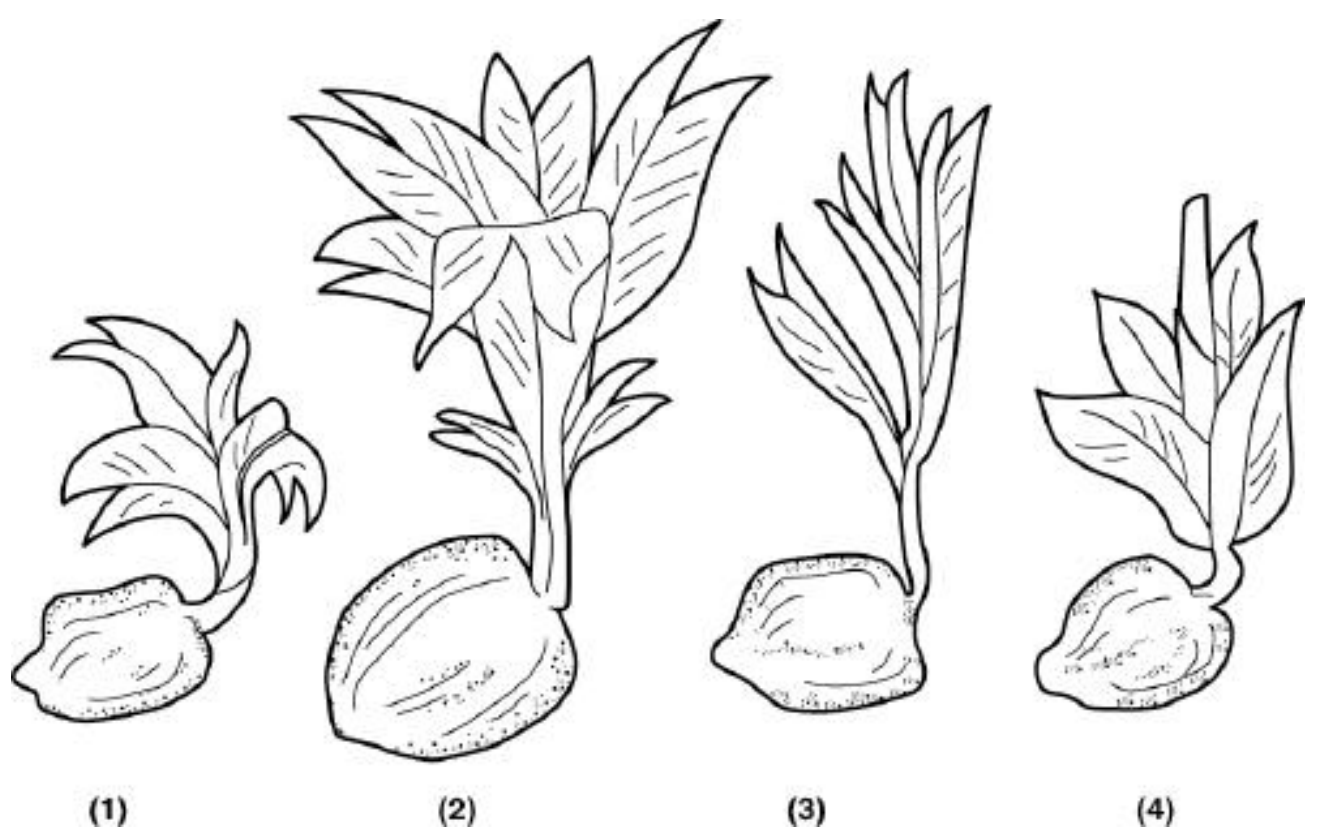

Figure 4. Selection of coconut (ni) seedlings. All seednuts sprouted at the same time and are 6 months old.

1. Discard-crooked twisted stem.

2. Select- tall, thick, strong, straight stalk and many large wide leaves.

3. D iscard-tall, but thin, weak stalk and narrow leaves.

4. Discard-very slow growing, will make a slow growing, poor yielding coconut (ni) palm.

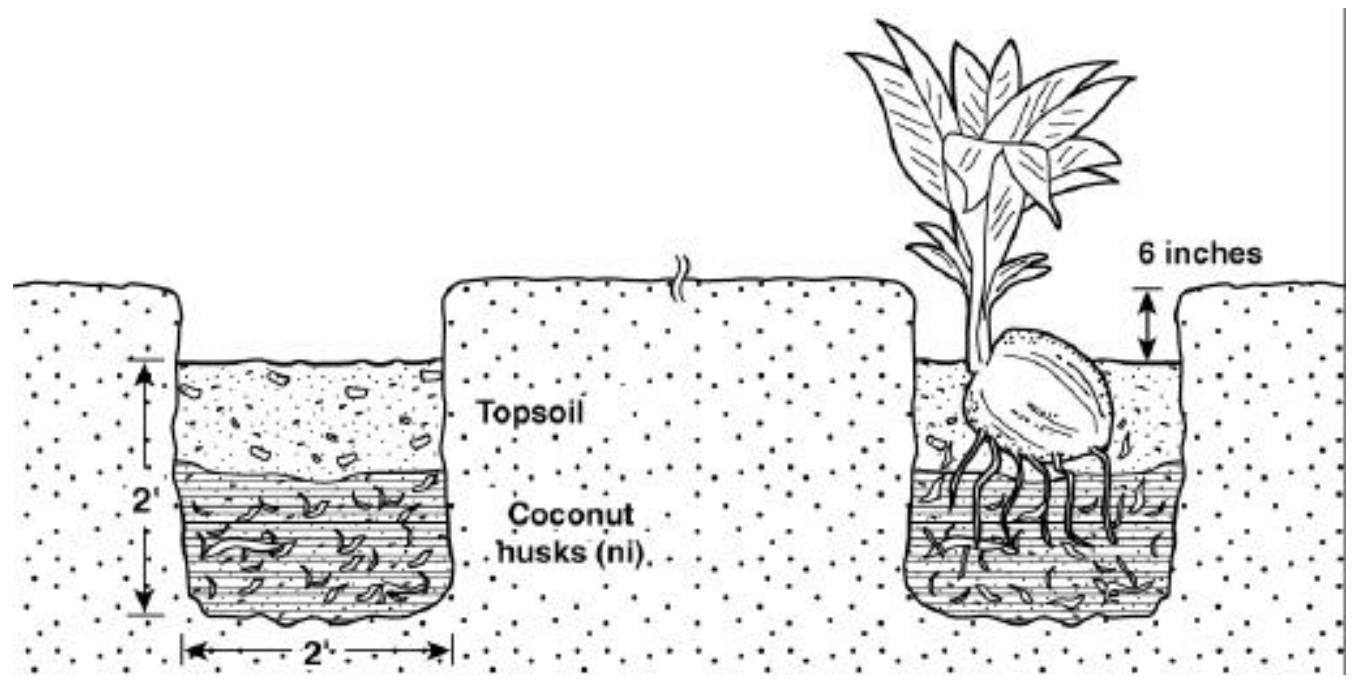

Figure 5. A useful method for hole preparation and planting of coconut (ni) seedlings. 


\section{Breadfruit (M a)}

It is believed that before the German traders arrived in the 1860s, there was more breadfruit (ma) in the Marshall Islands than coconuts (ni). Breadfruit ( $\mathrm{Ma}$ ) ranks as the least tolerant of atoll plants to soil salinity. Spray damage to breadfruit ( $\mathrm{ma}$ ) leaves is severe during typhoons, and salt water mixed with groundwater, either during storms or long droughts, will damage or kill trees. Some seeded varieties appear more tolerant to salt.

Seeded varieties can be propagated by placing seeds in a shaded nursery bed and watering as needed. When the seedlings are 12 to 20 inches tall, plant as described below.

All varieties can be propagated by root suckers or root cuttings. The most desirable root sucker is about 3 feet tall with small rootlets coming from the main root. Cut off a 15- to 20-inch piece of root containing the sucker, disturbing the small roots as little as possible. Keep moist until planted, as described below.

Larger numbers of plants can be obtained from root cuttings. Excavate surface roots 1 to 2.5 inches in diameter and cut these into 12- to 18-inch-long sections. Place these sections flat on a nursery bed in a shaded location, and cover with a heavy mulch to keep seedlings moist. Add water as needed. The cuttings will sprout and be ready for planting in 5 to 6 months.

Take considerable care in planting any of the above seedlings, especially near the low rainfall limit of breadfruit (ma). Select sites well away from exposed coasts and on the best soil available. Space trees 30 to 40 feet apart. For each, dig a hole about 2 feet square by 2 feet deep or larger. Place decayed organic matter in the lower half, then fill with good top soil to about 4 inches from the top. Plant the seedlings in this, covering the roots with good soil. Place 4 to 6 inches of mulch around the plant and water every two days in sunny weather until the plants are well established. Shade the plants for a month or more if they are in full sunlight.

\section{Banana (Binana, Kepran)}

Bananas (binana, kepran) grow well on good soils where rainfall is adequate, but are difficult to grow on atolls with a long dry season unless additional water can be provided. Of the two types of banana (binana, kepran), the cooking varieties seem to grow better than the eating varieties under dry conditions.

Three types of planting materials can be used for propagation (Figure 6):

1. Large suckers 4 to 8 feet tall.

2. Sword suckers (or "peepers") about 20 to 30 inches tall.

3. Old stumps of plants (sometimes called "bits").

Sword suckers are the usual planting material although large suckers will bear fruit sooner. Suckers should be removed from the parent plant by cutting with a sharp tool halfway between the two. The roots are then trimmed, all open leaves cut off, and the plants allowed to dry in the shade a few days until the cut surfaces heal.

For planning, select an area sheltered from wind and salt spray that has very good soil. Planting on low areas near fresh water-like the sides of an old taro (iaraj, kotak, wot) pit-is desirable especially on drier atolls. Or plant the suckers near a house if "gray water" can be diverted into a small planting during the dry season.

Banana plants should be spaced about 10 feet apart.

Soil preparation is important because bananas (binana, kepran) are sensitive to both drought and iron deficiency. A traditional and effective procedure is to dig a large pit, at least two feet square and three feet or so deep (Figure 7). Fill this half way with coconut (ni) husk and other organic materials. Fill the rest of the pit, up to about six inches from the top, with good surface soil. Plant the sucker in this good soil, packing it firmly around the roots. Then place a heavy mulch around the plant. Continuous mulching is necessary to provide the nutrients needed for good growth and fruit production.

\section{Pandanus (Bob)}

Until recent times, $P$ andanus (Bob) was one of the most important food plants for the people of Kiribati, the Marshall Islands, and the eastern Caroline Islands. It is 

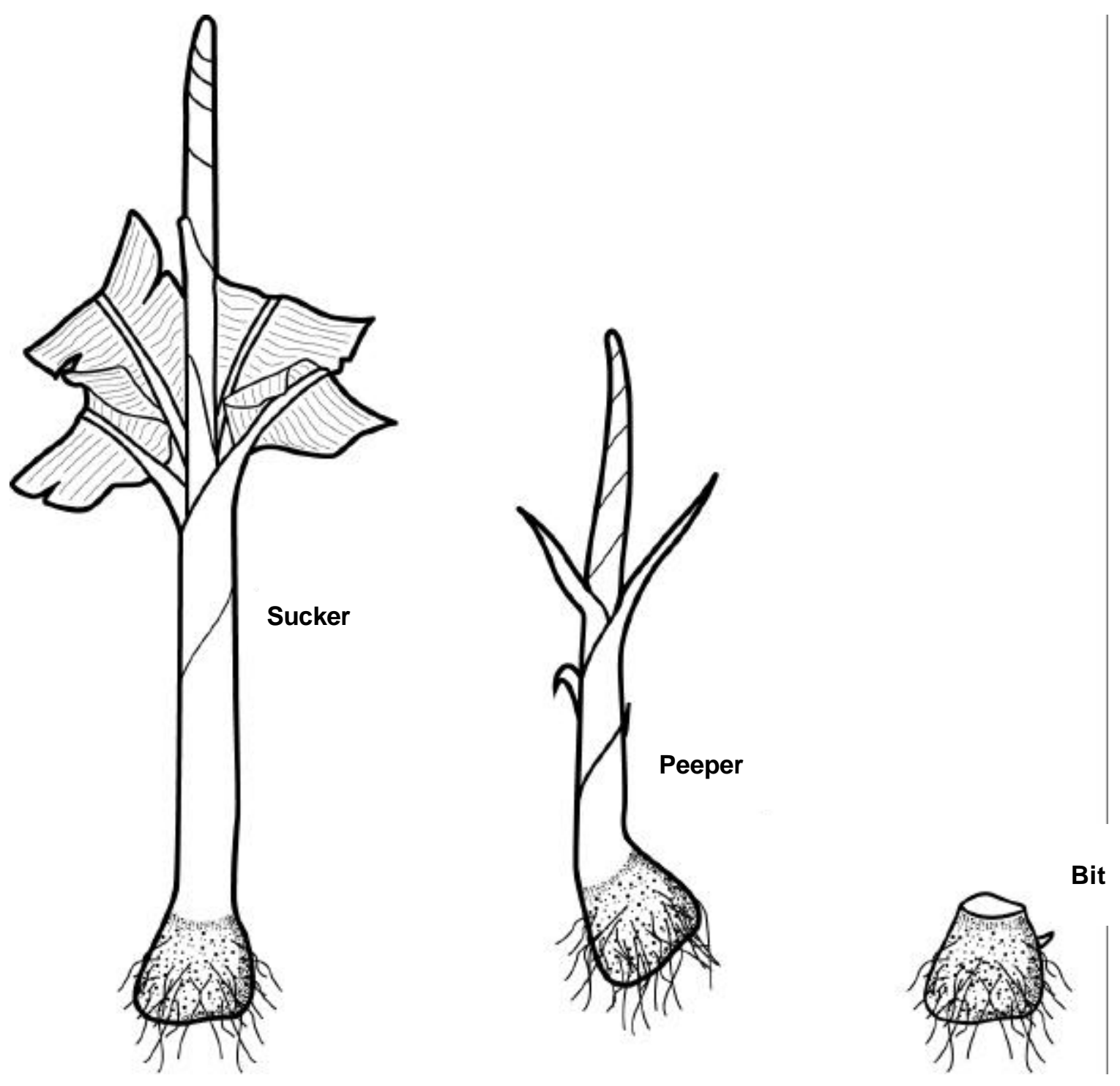

Figure 6. Three types of banana (binana, kepran) planting material. 


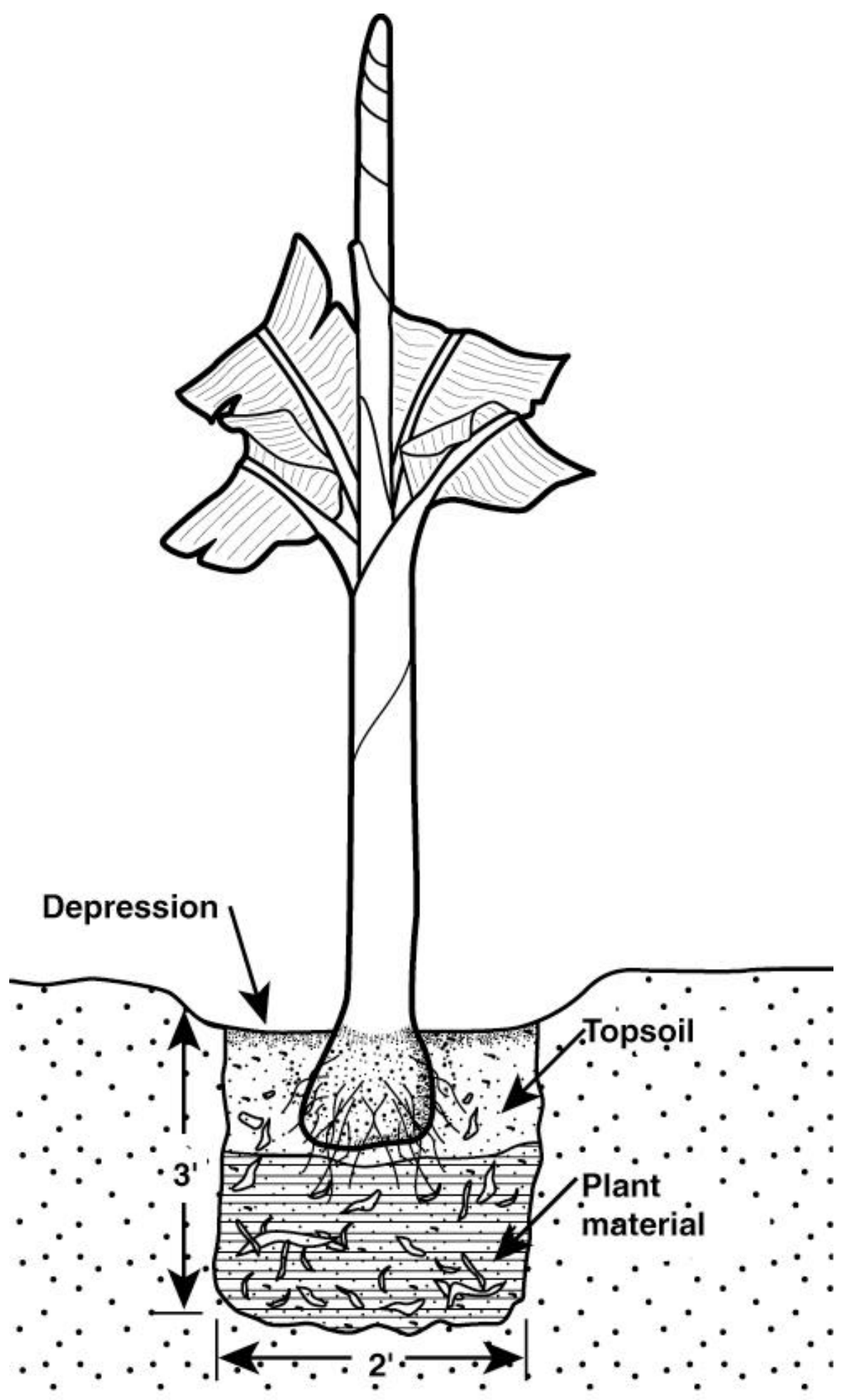

Figure 7. The correct method of planting a banana (binana, kepran) sucker. 
believed that $P$ andanus (bob) came to these islands before coconut (ni). The plant is extraordinarily tolerant of growing in a wide range of soil conditions on most parts of an atoll. It is highly tolerant of both soil salinity and salt spray, growing where other plants cannot survive. It is more tolerant of drought than coconut (ni). Its fruit may get smaller during very dry periods but usually it will continue to bear. There are a large number of varieties, some grown only for their fruit, others for their leaves.

Edible $P$ andanus (bob) varieties are propagated only by stem cuttings, since seedlings revert toward the wild form. Any branch can be used as propagating material, although branches that have already developed aerial roots are likely to grow faster. Any long roots are trimmed to fit in a planting hole and about two-third of the leaves are cut off to reduce water loss. Plants should eventually be spaced about 20 to 25 feet apart. They may be spaced closer in the beginning to form a coastal windbreak. On the drier atolls, the cuttings should be placed over pits containing organic matter, as described for coconut (ni). The time from planting to fruiting is usually 4 to 6 years, depending on variety and soil conditions.

\section{V egetable G rowing}

A small area of ground will grow enough vegetables for a whole family, provided that the area is productive and intensively managed. Such an area should have full sunlight and be free of roots from coconuts (ni) or other trees-which may reach out 60 to 75 feet from the trunk of the tree.

Lack of soil organic matter or humus is the limiting factor in growing vegetables in atoll soils. Bringing in black soil from wideisland interiors or elsewhere is seldom feasible. Garden soil can be greatly improved, however, by adding large quantities of organic materials each year.

When planting a row crop, such as Chinese cabbage (keebij), beans (piin), and sweet potatoes (biteto tonal), dig a row 10 inches deep and pack it half full of vine and leaves, especially those of Vigna (marckinjojo), or Canavalia (kana). Seaweed, sea cucumbers, or household garbage also can be used (Figure 8a). Cover this with soil, and plant the seeds or seedlings. Water the planted area as needed, and thin the plants to a proper spacing. For plants such as cucumber, melon, or pumpkin (banke), dig holes 10 to 12 inches deep, treat as above, and sow the seeds (Figure 8b).

The recommendations are consolidated in Table 3. Suitable treatments for many other kinds of plants are also suggested. 


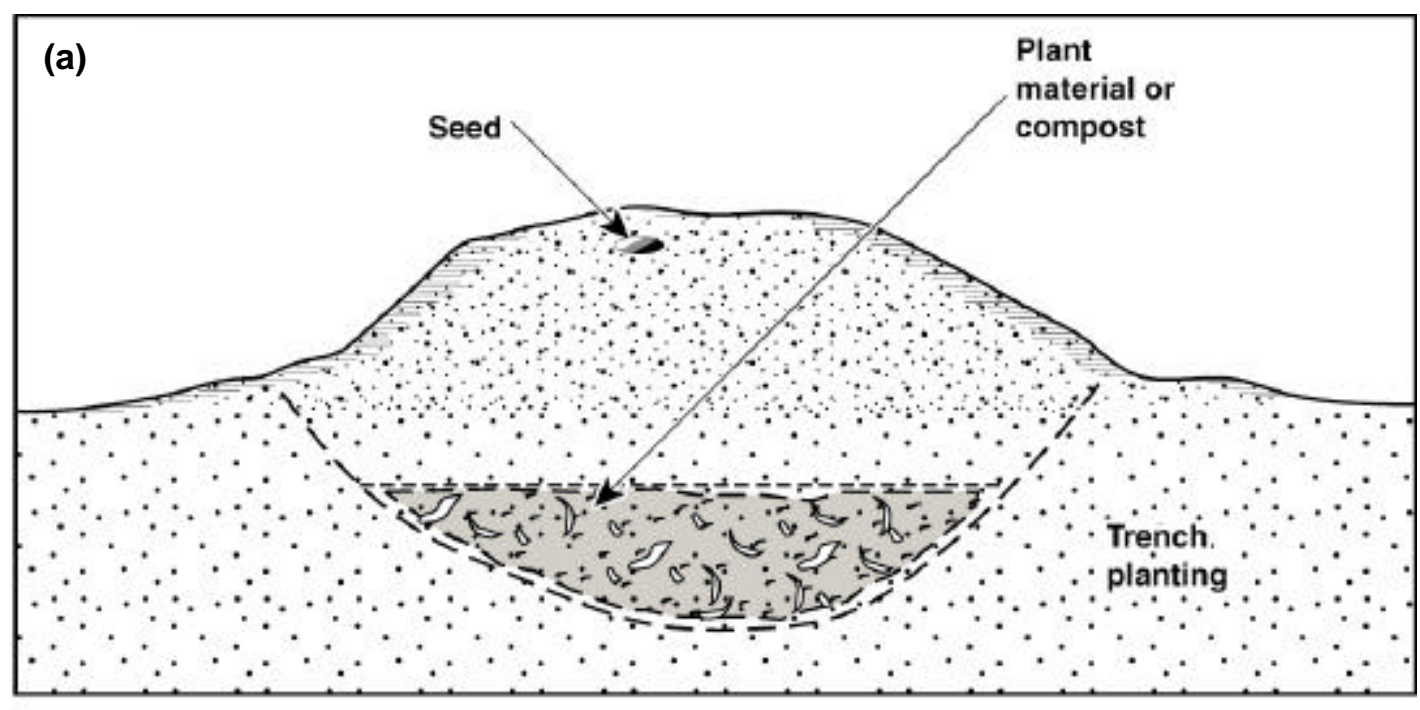

(b)

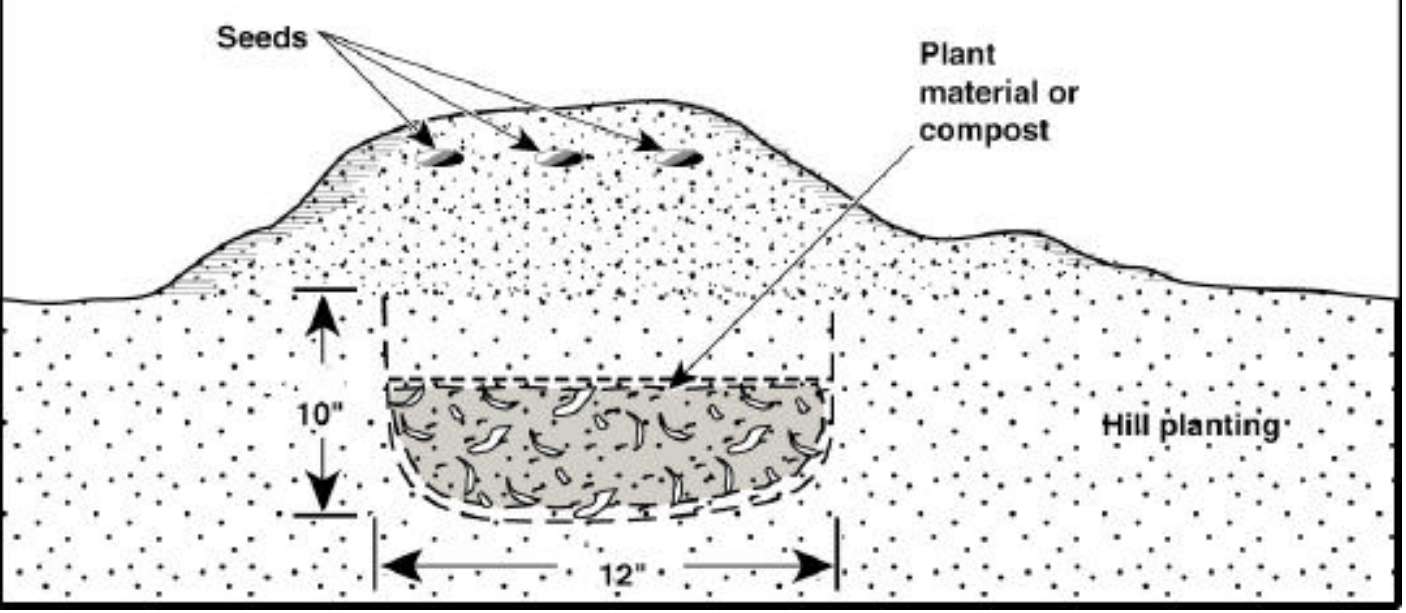

Figure 8. How to place compost or other plant material in (a) a trench below a row of plantings, or (b) beneath a hill of plantings. 


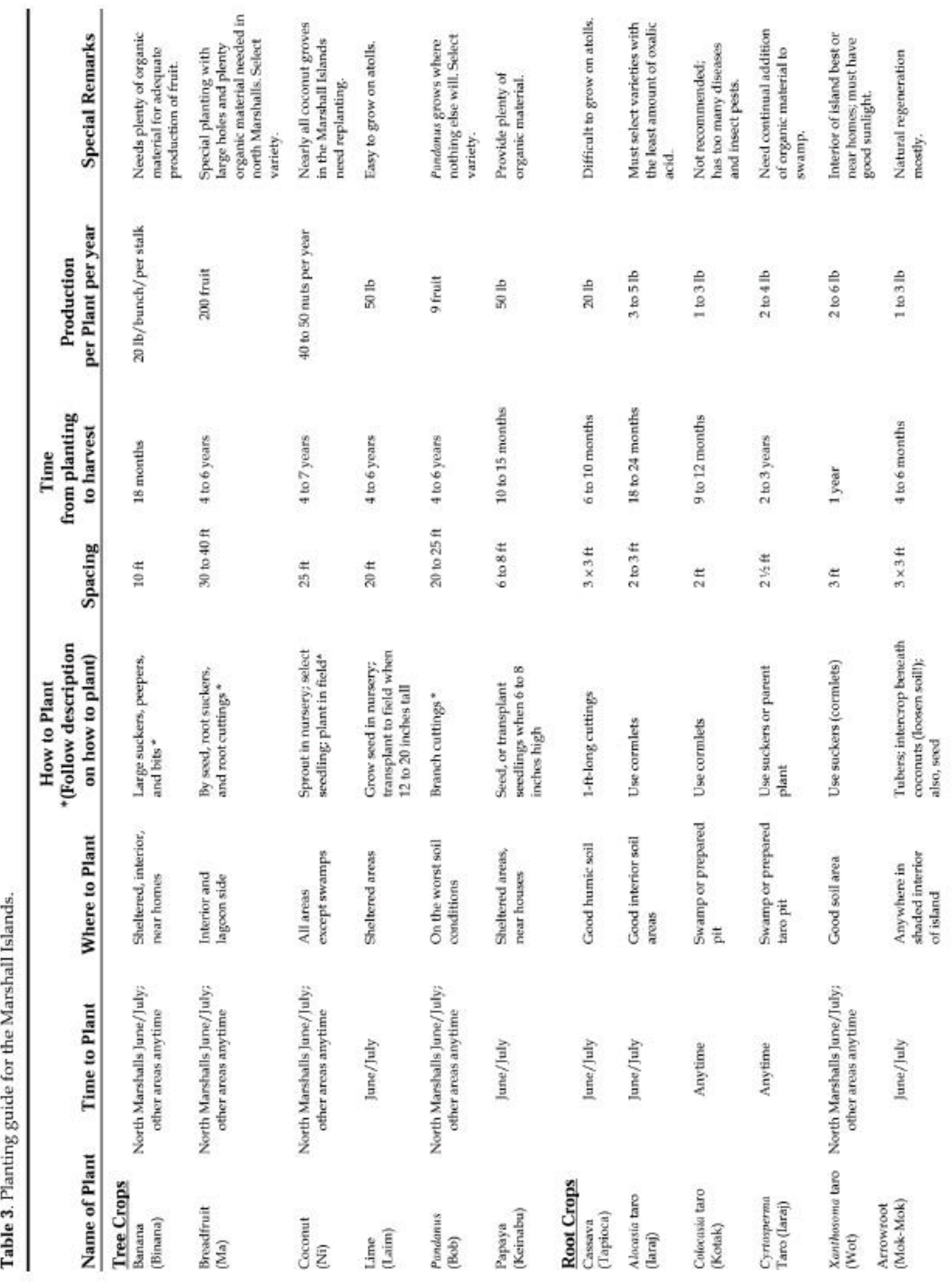




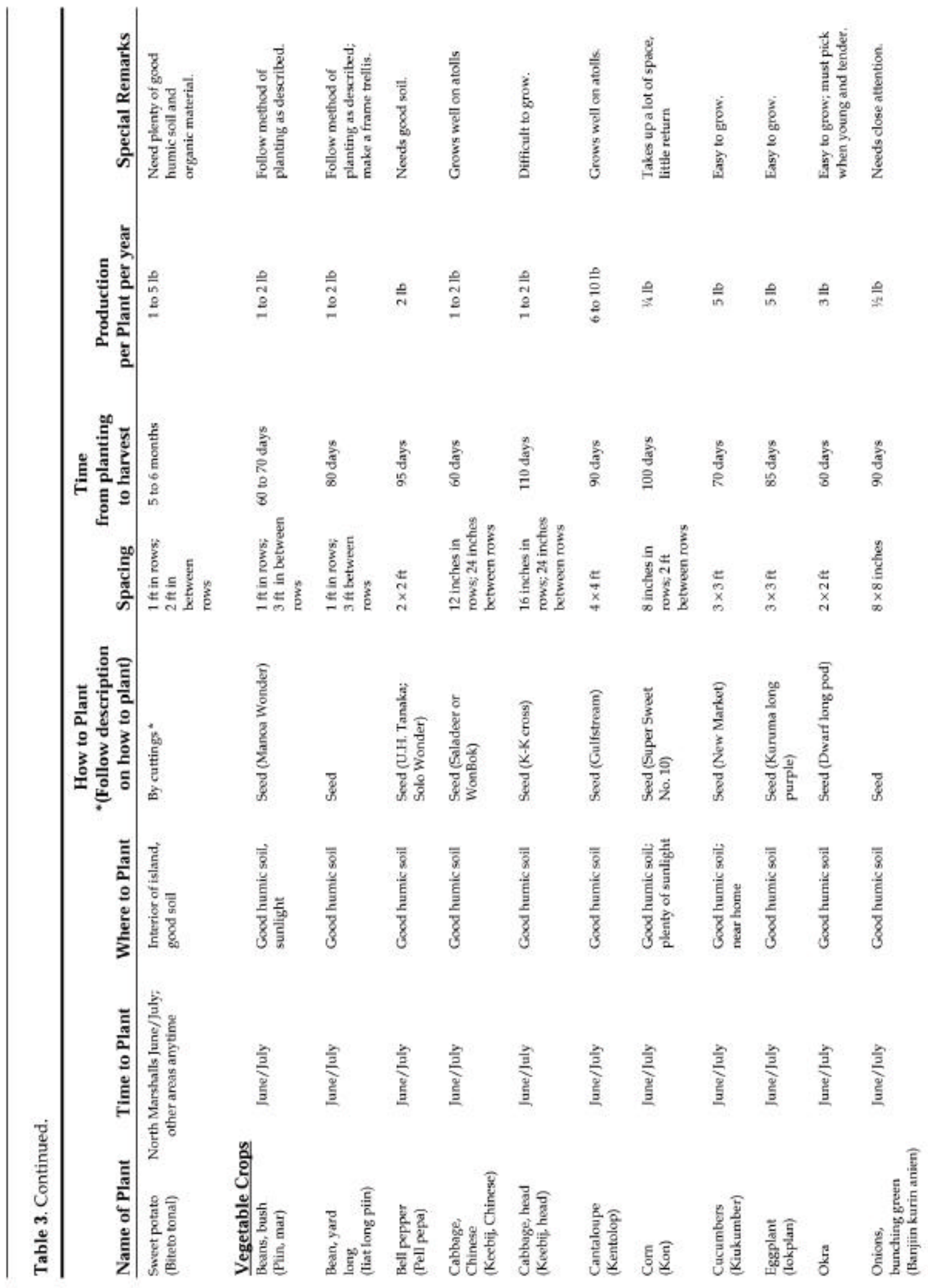




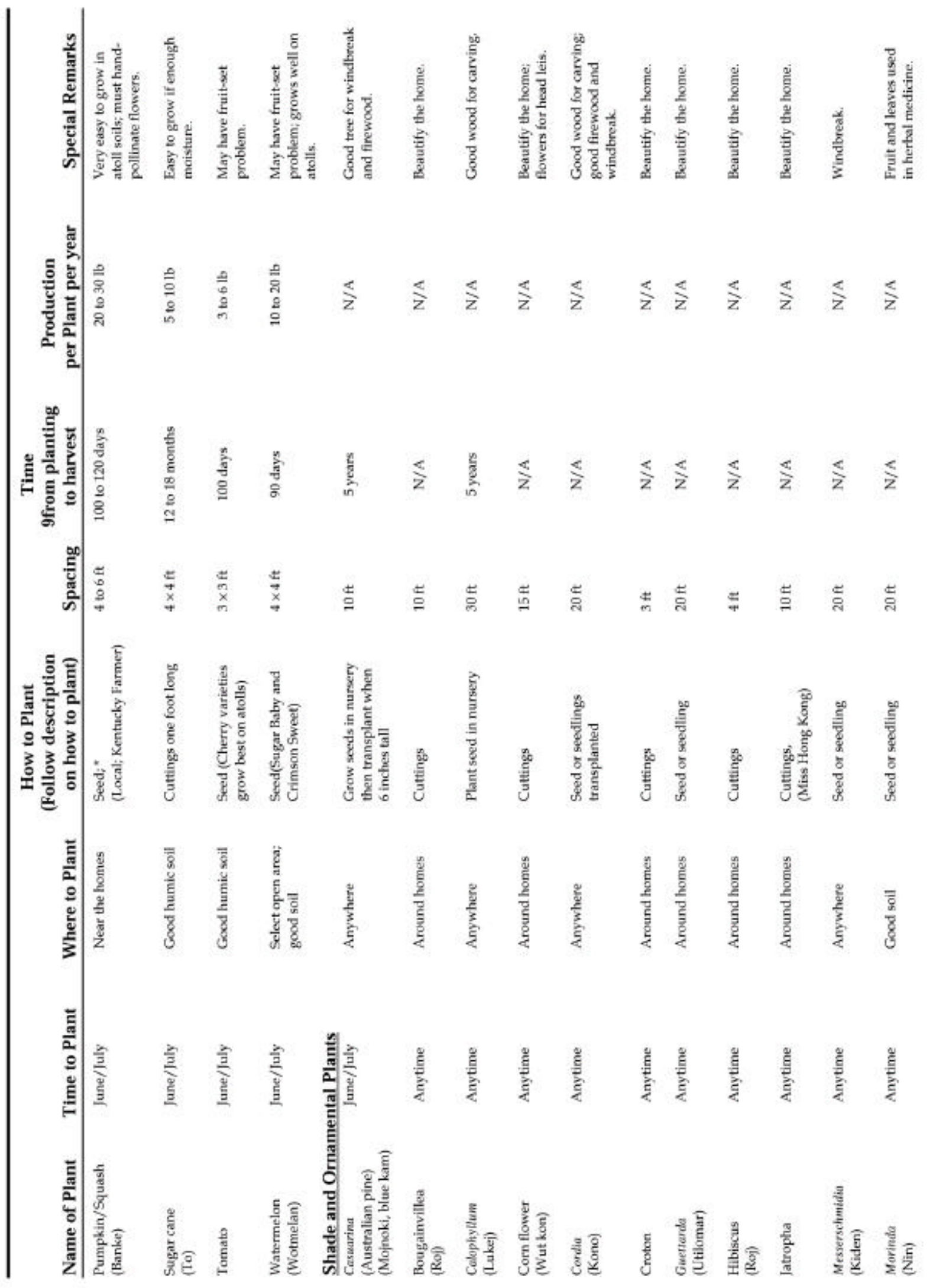




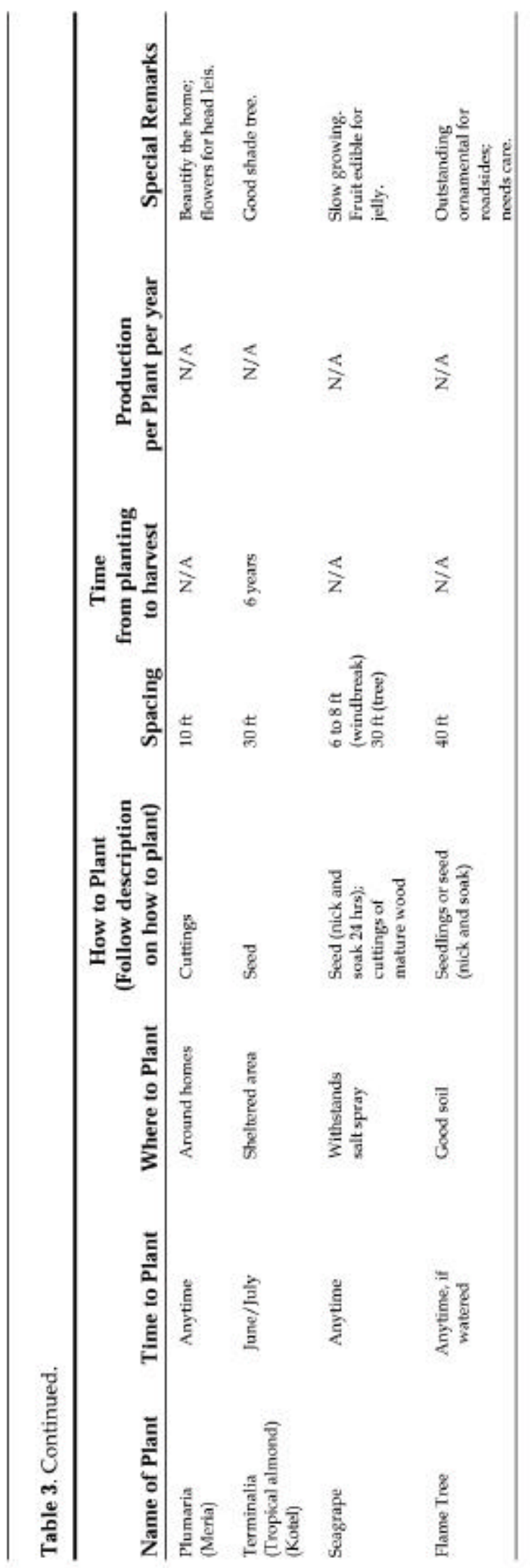

